\title{
Effect of music on blood pressure, pulse rate and respiratory rate of asymptomatic individuals: $A$ randomized controlled trial
}

\author{
Samitha Siritunga ${ }^{1^{*}}$, Kumudu Wijewardena $^{2}$, Ruwan Ekanayaka $^{3}$, Premadasa Mudunkotuwa $^{4}$ \\ ${ }^{1}$ National Institute of Health Sciences, Kalutara, Sri Lanka; *Corresponding Author: sssiritunga@yahoo.com \\ ${ }^{2}$ Department of Community Medicine, Faculty of Medical Sciences, University of Sri Jayawardhanapura, Nugegoda, Sri Lanka \\ ${ }^{3}$ Institute of Cardiology, National Hospital, Colombo, Sri Lanka \\ ${ }^{4}$ Department of Languages and Cultural Studies, University of Sri Jayawardhanapura, Nugegoda, Sri Lanka
}

Received 6 March 2013; revised 3 April 2013; accepted 14 April 2013

Copyright (C) 2013 Samitha Siritunga et al. This is an open access article distributed under the Creative Commons Attribution License, which permits unrestricted use, distribution, and reproduction in any medium, provided the original work is properly cited.

\section{ABSTRACT}

A slight reduction of blood pressure and heart rate can reduce the risk of developing cardiovascular disease. Maintenance of the respiratory rate within the normal range has also being identified as crucial for a healthy heart. Use of Indian and western music have been considered among many preventive programmes for long time in order to risk reduction associated with cardio vascular diseases. Therefore the aim of this study is to describe the effect of Indian classical music on systolic and diastolic blood pressure, pulse rate and respiratory rate in asymptomatic individuals aged 45 to 65 years. Methodology: A community based randomized intervention study was conducted in 252 asymptomatic individuals. The study group $(n=$ 127) listened to a music based on Indian classical system (entire track of 22 minutes). The control group $(n=125)$ was kept silent for a similar time period. Systolic and diastolic blood pressure, pulse rate and respiratory rate of each study participant were monitored before and after the intervention. Results: Statistically significant reduction in systolic blood pressure $(8.53 \mathrm{mmHg})$, diastolic blood pressure $(5.8 \mathrm{mmHg})$, pulse rate (5.16 breaths per minute) and respiratory rate (2.55 per minute) were observed in the study group after listening to the music $(p<0.01)$. In the control group, changes observed during the period of intervention were not significant $(p>$ $0.05)$. The reduction was independent of gender, age, education level, practicing a mind relaxation technique and preferred type of music of the participant. Conclusions: Listening to Indian classical music for about 22 minutes significantly reduced systolic and diastolic blood pressure, pulse rate and respiratory rate of asymptomatic individuals. Hence, music may have a potential benefit in cardio vascular disease preventive programmes.

Keywords: Music; Indian Classical; Asymptomatic Individual; Blood Pressure; Pulse Rate; Respiratory Rate

\section{BACKGROUND}

Cardio vascular diseases (CVD) are the leading causes of death in the world. According to the World Health Organization, in 2008, the number of people who died of ischaemic heart disease (IHD) and of cerebrovascular disease such as stroke was approximately 7.3 and 6.2 million, respectively [1]. It has been shown that a slight reduction of blood pressure leaded to a reduction in prevalence of morbidity and mortality associated with cardiovascular diseases [2-6]. In the general population, a reduction of resting heart rate leads to a reduction in CVD risk as well as its consequences [7-10]. Furthermore, several studies have indicated the beneficial effects of maintenance of the respiratory rate within the normal range for a healthy heart $[11,12]$.

Since the clinical care of CVD is costly and prolonged, prevention of CVD is crucial. It helps to improve the quality of life as well as increased life expectancy of the patient. Currently, health related costs of CVD accounts for a larger proportion of the health budgets and will probably utilize the largest proportion of health budgets in future [13-15]. Therefore the impact on a country's economy by preventing the development of CVD is 
likely to be enormous.

\section{Music Therapy in Cardio Respiratory Physiology}

There are many preventive programmes operating to minimise the development of CVD mainly based on life style modification. Approaches aimed at reducing stress and anxiety such as music therapy, muscle relaxation therapy, meditation, biofeedback etc. are now being seriously considered [16]. Music therapy includes music improvisation, receptive music listening, song writing, lyric discussion, imagery and relaxation and performance of music [17]. According to the scientists, the effect of relaxing music is due to complex neurophysiological phenomenon which affects the entire nervous system and stress hormones [18]. Music therapy is easy to practice; prior preparations are not needed and it can be practiced at any given time; thus it is more acceptable to the general population. Further, it is safe [19] and is an extremely inexpensive intervention technique [20].

While western and eastern classical music systems have a positive effect on the physiology and the psychology of the human body, rock, pop, jazz, rap, disco and other varieties of fast and high-beat music which have become quite popular in the modern times, are found to have detrimental effects on health in general [18,21-23]. Though the effect of relaxation music on physical health has been identified since ancient times [18,24,25], no published studies are available from Sri Lanka. Most of the studies conducted elsewhere have small sample sizes [21,26,27]. They have compared the effect of different types of music, which were played only for a short period of time usually less than 10 minutes [21,26] even though at least 20 minutes of music was used in most of the previous studies conducted in other areas of interest [16,28,29].

Moreover, studies have been conducted to investigate effects outside the scope of cardiorespiratory effects of music extended into the psychological and hormonal impact $[21,26,27]$. The results have varied from study to study. Some of the studies of music on heart rate or blood pressure are inconclusive [26,27]. The study done by Bernardi L. et al. was able to demonstrate a significant effect of different types of music on heart rate and the blood pressure in musicians and non-musicians [21]. According to the research, slower or more meditative music such as raga music had significant effect on reducing the heart rate while faster music and more complex rhythms such as rap, techno and fast classical had significant effect on increasing the respiratory rate, heart rate and blood pressure [21]. In fact, some researchers have suggested that further studies to be done with more scientific basis $[16,30]$. Therefore, the aim of our study was to determine the effects of Indian classical music on systolic and diastolic blood pressure, pulse rate and respiratory rate in asymptomatic individuals aged 45 to 65 years.

\section{METHODS (FIGURE 1)}

A community based randomised intervention study was conducted on a sample of 252 calculated for effect size of $5 \mathrm{mmHg}$ of diastolic blood pressure at $\alpha=0.05$ and power at 0.9 (90\%) after obtaining the of ethics review committee of University of Sri Jayawardhanapura, Sri Lanka.

Men and women between 45 and 65 years of age who

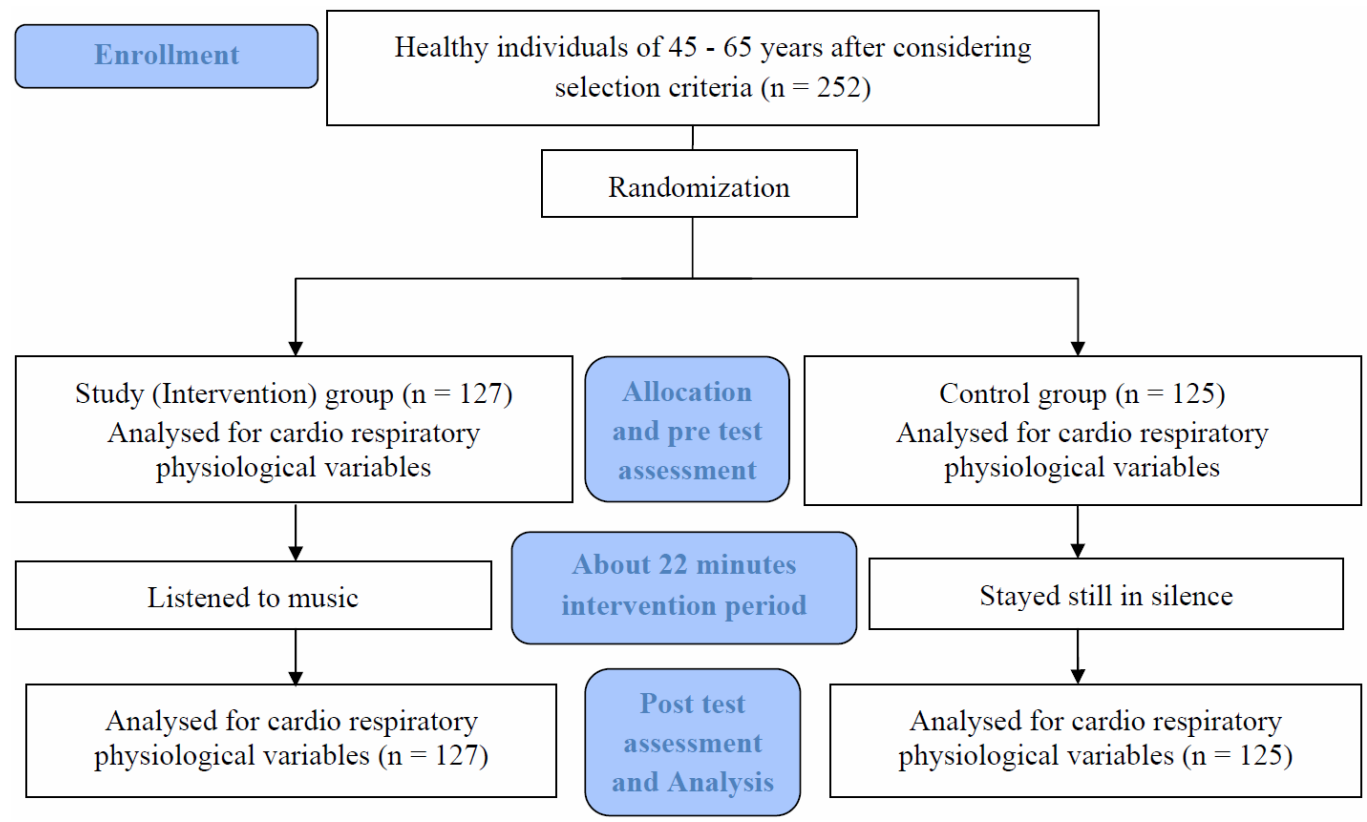

Figure 1. Methodology. 
were not on any long term treatment and who had not been diagnosed as having a long term illnesses living in the study area, at the time of data collection were considered as the study sample. People who were on dietary or life style modifications for any long term illness were excluded. Individuals whose resting pulse rate was less than 60 beats per minute (bpm) and more than 100 (bpm), blood pressure above 140/90 mmHg, and people with additional heart sounds and with hearing impairment were also excluded.

Random sampling method was used to draw the sample. All the identified individuals were screened for pulse rate, blood pressure, heart sounds and hearing. The individuals who fulfilled the selection criteria at the screening were selected for the intervention component of the study after obtaining their informed written consent.

All data collectors underwent training for the special tasks required in the research such as identifying the appropriate individuals from the community to make the sample frame and obtaining the accurate measurements of systolic blood pressure, diastolic blood pressure, pulse rate and respiratory rate.

\subsection{Data Collection}

A pre-tested, self-administered questionnaire was used to obtain basic socio-demographic data and interested in music of the participants.

The systolic and diastolic blood pressure, pulse rate and respiratory rate were measured in the seated position after resting comfortably about 30 minutes. Each measurement was repeated once and the mean was taken for the analysis.

Pulse rate and blood pressure were obtained by using digital blood pressure apparatus (OMRON IA-2 model). Respiratory rate was determined by counting the respiratory movements of the chest for one minute from a distance [31,32].

Examination of hearing was done during screening by using a simple hearing examination technique (whispered voice test) [32] and this was performed to ensure that the selected individuals had no major hearing impairment, which might have any effect on listening.

The intervention component was carried out in an air- conditioned room with calm and quiet environment in soft lighting. To obtain accurate results, especially the blood pressure, the participants were asked to avoid coffee/caffeine for at least 1 hour before the test and avoid smoking 30 minutes before the test. By restricted randomization technique, 127 and 125 individuals respectively were recruited to the study (intervention) and control groups.

\subsection{Intervention}

About 22 minute music track based on Indian classical Rag Darbari Kanada which had been identified as having effective for cardio vascular system with empirical studies [33] was used as the intervention. Each individual was examined for blood pressures, pulse rate and respiratory rate, repeated once again after 3 minutes. Music was listened by using head phones connected to a head phone divider seated in a comfortable position. At the $19^{\text {th }}$ minute, the post test measurements were obtained by the trained medical officers, repeated 3 minutes later i.e. at the $22^{\text {nd }}$ minute. Same settings were used for the control group except listening to music. They were asked to stay still in silence for 22 minutes and the group was also assessed in the same way as the intervention group for blood pressure, pulse rate and the respiratory rate.

The significant level of a statistical test was considered as 0.01 and 0.05 . Independent $t$ test was used to compare means of study and control groups while paired $\mathrm{t}$ test was used to compare pre and post test results of the same group.

\section{RESULTS AND DISCUSSION}

\subsection{Socio Demographic Characteristics}

Both study and control groups were approximately similar in measured socio demographic characteristics (Table 1). Female to male ratio was 1.08:1. About 60\% were between 45 to 55 years. Majority were Sinhalese and Buddhist in religion. About 92\% were married. While all had either primary or secondary level education and majority indicated that they were neither current smokers nor current alcohol drinkers.

Table 1. Participants' characteristics.

\begin{tabular}{|c|c|c|c|}
\hline Characteristic & & Study $(n=127)$ & Control $(n=125)$ \\
\hline Gender & Female:Male & 1.08:1 & 1.08:1 \\
\hline Age $(\%)$ & $45-55 / 56-65$ & $63 / 37$ & $60 / 40$ \\
\hline Ethnicity (\%) & Sinhalese/Others & $79.5 / 20.5$ & $79.2 / 20.8$ \\
\hline Religion (\%) & Buddhist/Others & $73.2 / 26.8$ & $70.4 / 29.6$ \\
\hline Marital status (\%) & Married/Unmarried & 92.9/7.1 & $92.0 / 8.0$ \\
\hline Education level (\%) & Primary/Secondary & $42.5 / 57.5$ & $40 / 60$ \\
\hline Current employment status (\%) & Employed/Unemployed & $51.2 / 48.8$ & $48.8 / 51.2$ \\
\hline Current smoking status (\%) & Smoking/Not smoking & $9.4 / 90.6$ & $10.4 / 89.6$ \\
\hline Current alcohol drinking status (\%) & Drinking/Not drinking & $13.4 / 86.6$ & $14.4 / 85.6$ \\
\hline
\end{tabular}




\subsection{Interest in Music and Practicing a Kind of Relaxation Technique}

Over $95 \%$ of participants in each group were fond of music. Of the individuals in the study and control groups, more than 95\% have identified the need for a mind relaxation technique. But only about $50 \%$ of the study group and about $60 \%$ of the control group indicated that they were practicing any kind of mind relaxation technique.

\subsection{Cardio Respiratory Physiological Variables}

Before the intervention, study and control groups were not significantly different for systolic blood pressure (126.1 vs $123.2 \mathrm{mmHg}$ ), diastolic blood pressure (77.2 vs $76.0 \mathrm{mmHg}$ ), pulse rate (77.5 vs 77.4 beats per minute) and respiratory rate (15.2 vs 14.4 per minute) (p > 0.05).

After the intervention, the mean systolic blood pressure dropped to 117.5 (mmHg) from 126.1 (mmHg) and the diastolic blood pressure dropped to 71.4 (mmHg) from 77.2 (mmHg) in the study group. A reduction of mean pulse rate to 72.3 (bpm) and respiratory rate to 12.7 (per minute) was also recorded and all these changes in all measurements were significant $(<0.01)$. The changes observed in the control group; systolic blood pressure from 123.2 (mmHg) to 123.0 (mmHg), diastolic blood pressure from 76.0 (mmHg) to 76.8 (mmHg), pulse rate from $77.4(\mathrm{bpm})$ to $76.9(\mathrm{bpm})$ and respiratory rate from 14.4 to 15.0 (per minute) were not significant $(>0.05)$.

The intervention group demonstrated significant reductions ( $p<0.01$ ) of mean systolic blood pressure by $8.6 \mathrm{mmHg}$ (126.1 vs 117.5) and mean diastolic blood pressure by $5.8 \mathrm{mmHg}$ (77.2 vs 71.4) irrespective of various socio demographic and behavioural factors. Similarly, a significant reduction of mean pulse rate by 5.2 beats per minute (77.5 vs 72.3 ) and mean respiratory rate by 2.5 per minute (15.2 vs 12.7 ) was also observed after the intervention. Conversely, the control group did not show any significant change in any of the parameter over the study (>0.05); systolic blood pressure 123.2 vs 123.0 $\mathrm{mmHg}$, diastolic blood pressure from 76.0 vs $76.8 \mathrm{mmHg}$, pulse rate 77.4 vs 76.9 bpm, respiratory rate 14.4 vs 15.0 per minute. At the same time, the difference of post test results for each measurement between two groups was significant ( $<$ 0.01) (Table 2). This confirmed that music has a significant impact on cardio respiratory physiology compared to staying still in silence.

Population based studies have indicated the association of lower risk of developing hypertension, coronary heart disease, stroke as well as lowering the mortality risk from vascular disease with lowered blood pressure by 2 - $6 \mathrm{mmHg}[2-5,34]$. A reduction in systolic blood pressure by $8.53 \mathrm{mmHg}$ and diastolic blood pressure by $5.8 \mathrm{mmHg}$ after listening to music was revealed in our study which is beneficial.

Studies have shown the association of increase risk for coronary heart disease with heart rate more than 84 beats per minute at rest [10,35]. Increase risk of mortality in the general population as well as in post myocardial infarction (MI) patients have also been identified with increasing heart rate $[9,10,35]$. Conversely, a $25 \%$ - 30\% decrease of infarct size occurs with decrement of heart rate by 14 beats per minute [35]. Moreover, the risk of increased mortality has been identified with increasing heart rates in post MI patients. In our study, the mean pulse rate of all participants before and after intervention was less than 77 bpm which means all our participants were at a lower risk of developing CVD. Further, in our study, listening to music for 22 minutes induces a drop in the mean pulse rate by $5.2 \mathrm{bpm}$ which is favourable in reducing further $C V D$ risk.

Usually, the normal adult breathing rate is 8 - 20 breaths per minute at rest [36,37]. Most modern adults breathe much faster (about 15 - 20 breaths per minute) than their normal respiratory rate (36). Respiratory rates in the sick are usually higher, generally about 20 breaths/ min or more (36). Studies have revealed that an increased respiratory rate up to about 15 breaths per minute occur in patients with heart disease (12). When compared the results of current study, all our participants were at a lower risk for CVD and related disease. But results of our study show further reduction of respiratory rate by 2.6 per minute after listening to music which is more favorable for a healthy heart as well as for a healthy life.

The observed effect may be due to the effect of music on the central and autonomic nervous system as well as on the endocrine system with resultant reduction in the

Table 2. Influence of intervention on cardio respiratory physiological variables.

\begin{tabular}{|c|c|c|c|c|c|c|}
\hline \multirow{2}{*}{ Variable } & \multicolumn{3}{|c|}{ Study group $(n=127)$} & \multicolumn{3}{|c|}{ Control group $(n=125)$} \\
\hline & Pre test & Post test & $\mathbf{p}^{*}$ & Pre test & Post test & $\mathbf{p}^{*}$ \\
\hline Mean systolic BP (SD) mmHg & $126.1(12.4)$ & 117.5 (10.9) & $<0.01$ & $123.2(13.3)$ & $123.0(13.7)$ & $>0.05$ \\
\hline Mean diastolic BP (SD) mmHg & $77.2(8.9)$ & $71.4(7.4)$ & $<0.01$ & $76.0(8.2)$ & $76.8(8.8)$ & $>0.05$ \\
\hline Mean pulse rate (SD) bpm & 77.5 (11.9) & $72.3(9.2)$ & $<0.01$ & $77.4(11.7)$ & $76.9(11.2)$ & $>0.05$ \\
\hline Mean respiratory rate (SD) per min & $15.2(3.1)$ & $12.7(2.6)$ & $<0.01$ & $14.4(2.3)$ & $15.0(9.2)$ & $>0.05$ \\
\hline
\end{tabular}

* Paired t test. 
sympathetic activity with simultaneous activation of parasympathetic drive along with the reduction of stress hormone levels. Therefore, measuring the parallel effect of music on change of neuro endocrine system would also play an important role in understanding the underline physiology of the relaxation music. Almost all studies including our study were concerned more about the immediate effect of music on various physiological parameters. Hence future researches need to be extended to assess the sustainability of the effect of music. In addition, conducting researches to find out the effect of long term listening to the music on prevalence and the prognosis of cardio vascular disease is also important.

\section{CONCLUSION}

Significant reductions of systolic and diastolic blood pressure, pulse rate and respiratory rate were observed immediately after listening to Indian classical music for about 22 minutes in asymptomatic individuals aged between 45 and 65 years. Hence staying still in silence for the same duration had no significant impact on the cardio respiratory parameters. As these reductions were similar to the recommended reductions of the same in the evidence available, music can be considered for the use of programmes in preventing cardio vascular disease. As listening to relaxing music would be more acceptable to general population as an intervention method of reducing CVD risk, it would lead to an improvement in the quality of life of the people. Furthermore, as it is a very cost effective intervention method, it may help to minimise the CVD related economic burden in future.

\section{ACKNOWLEDGEMENTS}

We thank Professor R. Sooriarachchi, Department of Statistics, University of Colombo, Sri Lanka for the assistance and guidance given in the calculation of the sample sizes for the study, the National Health Research Council, Sri Lanka for supporting financially a part of this study and for giving technical guidance, director and the staff of the National Institute of Health Sciences, Kalutara, Sri Lanka for giving necessary facilities to conduct the study and all participants of the study for the support given to conduct it.

\section{REFERENCES}

[1] WHO (2012) Top 10 causes of death. http://www.who.int/mediacentre/factsheets/fs310/en/inde $\underline{\mathrm{x} 2 . h \mathrm{tml}}$

[2] Wikimedia Foundation (2006) Hypertension. http://en.wikipedia.org/wiki/Hypertension

[3] US Department of Health and Primary Services (2007) Approaches to primary prevention of hypertension. http://www.nhlbi.nih.gov/health/prof/heart/hbp/pphbp.pdf

[4] Eastern Stroke and Coronary Heart Disease Collaborative Research Group (1998) Blood pressure, cholesterol and stroke in eastern Asia. Lancet, 352, 1801-1807. doi:10.1016/S0140-6736(98)03454-0

[5] MacMahon, S. (2000) Blood pressure and the risk of cardiovascular disease. The New England Journal of Medicine, 342, 49-52. doi:10.1056/NEJM200001063420109

[6] International Task Force for Prevention of Coronary Heart Disease (2007) Management of hypertension: Coronary heart disease: Reducing risk.

www.chd-taskforce.com/guidelines/kap35.htm

[7] Borer, J.S. (2008) Heart rate: From risk marker to risk factor. European Heart Journal, 10, F2-F6. doi:10.1093/eurheartj/sun019

[8] Palatini, P., et al. (2006) Heart rate as a predictor of development of sustained hypertension in subjects screened for stage 1 hypertension: The HARVEST study. Journal of Hypertension, 24, 1873-1880. doi:10.1097/01.hjh.0000242413.96277.5b

[9] Hjalmarson, A.K. (2007) Heart rate: An independent risk factor incardiovascular disease. European Heart Journal Supplements, 9, F3-F7. doi:10.1093/eurheartj/sum030

[10] Reil, J.C., et al. (2011) Heart rate reduction in cardiovascular disease and therap. Clinical Research in Cardiology, 100, 11-19. doi:10.1007/s00392-010-0207-x

[11] What is heart disease? What causes heart disease? How to reverse heart disease? (2011) http://www.normalbreathing.com/diseases-Heart.php

[12] Artour, R.D. (2011) Heart disease means heavy and deep breathing 24/7: And how to reverse overbreathing using the Buteyko self-oxygenation breathing method breathing problems solved.

http://breathingproblems.wordpress.com/article/heart-dise ase-means-heavy-and-deep-dv4y2tahxi5j-4/

[13] Fernández, R.L., et al. (2006) Cost of cardiovascular diseases in the United Kingdom. BMJ Heart, 92, 13841389. doi:10.1136/hrt.2005.072173

[14] Liu, J.L.Y., et al. (2002) The economic burden of coronary heart disease in the UK. BMJ Heart, 88, 597-603. doi:10.1136/heart.88.6.597

[15] Ministry of Healthcare Nutrition and Uva-Wellassa Development (2005) Economy and health; taking Sri Lanka towards the global best. Ministry of Healthcare, Nutrition and Uva-Wellassa Development, Colombo.

[16] White, J. (1999) Effects of relaxing music on cardiac autonomic balance and anxiety after acute myocardial infarction. American Journal of Critical Care, 8, 220-230.

[17] Yale Medical Group (2005) Alternative therapy-Art therapy, dance therapy, music therapy, and imagery. http://www.yalemedicalgroup.org/stw/Page.asp?PageID= STW025835

[18] Jyothi, A. (2004) Healing by music therapy—Ragas. http://akhandjyoti.org

[19] American Cancer Society (2008) Music therapy. http://www.cancer.org/Treatment/TreatmentsandSideEffe cts/ComplementaryandAlternativeMedicine/MindBodyan dSpirit/music-therapy

[20] Iriarte Roteta, A. (2003) Music therapy effectiveness to decrease anxiety in mechanically ventilated patients. En- 
fermeria Intensiva, 14, 43-48. doi:10.1016/S1130-2399(03)78103-6

[21] Bernardi, L., Porta, C. and Sleight, P. (2006) Cardiovascular, cerebrovascular and respiratory changes induced by different types of music in musicians and non-musicians: The importance of silence. Heart Journal, 92, 445-452. doi:10.1136/hrt.2005.064600

[22] Laurance, O. (1999) Music and the brain. http://www.cerebromente.org.br/n15/mente/musica.html

[23] Watkins, T. (2006) Is music neutral? http://www.av1611.org/neutral.html

[24] Chiu, P. and Kumar, A. (2003) Music therapy: Loud noise or soothing notes? International Pediatrics, 18, 204-208.

[25] Sarim, T.V. (2002) Healing with music. http://www.the-south-asian.com

[26] Mockel, M., et al. (1994) Immediate physiological responses of healthy volunteers to different types of music: Cardiovascular, hormonal and mental changes. European Journal of Applied Physiology and Occupational Physiology, 68, 451-459. doi:10.1007/BF00599512

[27] Basagaoglu, I., Kalkan, M. and Sari, N. (2004) The physiological and psychological effects of classical music and pop music on female high school students. Yeni Symposium, 42, 82-90.

[28] Groß, W., Linden, U. and Ostermann, T. (2010) Effects of music therapy in the treatment of children with delayed speech development-Results of a pilot study. $B M C$
Complementary and Alternative Medicine, 10, 39. doi:10.1186/1472-6882-10-39

[29] ICBS Inc. (2007) Stress the silent killer. http://holisticonline.com/stress/stress_home.htm

[30] Bally, K. (2003) Effects of patient controlled music therapy during coronary angiography on procedural pain and anxiety distress syndrome: A clinical article. Critical Care Nurse, 23, 50-57.

[31] Kumar, P. and Clerk, M. (2001) Clinical medicine: A textbook for medical students and doctors. 4th Edition, W.B.Saunders, Edinburgh.

[32] Michel, S. (1995) Hutchison's clinical methods. 20th Edition, Saunders Company, London.

[33] Mudunkotuwa, P. (2006) Music therapy. Siritunga, T.L.S.S., Ed., Bhathkhande Sangeeth Vidyapith, Sri Lanka.

[34] Bandolier (2006) Preventing hypertension. http://www.medicine.ox.ac.uk/bandolier/band107/b107-6. $\underline{\mathrm{html}}$

[35] Singh, B.N. (2003) Increased heart rate as a risk factor for cardiovascular disease. European Heart Journal, 5, G3G9. doi:10.1016/S1520-765X(03)90001-0

[36] Rakhimov, A. (2011) Normal respiratory rate and ideal breathing. http://www.normalbreathing.com/index-rate.php

[37] Wikimedia Foundation (2012) Respiratory rate. http://en.wikipedia.org/wiki/Respiratory rate

\section{LIST OF ABBREVIATIONS}

CVD: Cardio Vascular Diseases

IHD: Ischaemic Heart Disease

MI: Myocardial Infarction

Bpm: Beats per minutes

\section{AUTHORS' CONTRIBUTION}

\begin{tabular}{ll}
\hline Samitha Siritunga & $\begin{array}{l}\text { Principal investigator. Has contributed in planning and designing the study as well as in the data } \\
\text { collection, analysis, interpretation, report writing and also in drafting the manuscript. }\end{array}$ \\
Kumudu Wijewardena & $\begin{array}{l}\text { Has contributed in designing, interpreting data and giving important intellectual content } \\
\text { especially on planning and also in reviewing the manuscript. }\end{array}$ \\
Ruwan Ekanayaka & $\begin{array}{l}\text { Has contributed in the designing, interpreting data and giving important intellectual content } \\
\text { especially on aspects in clinical cardiology and also in reviewing the manuscript. }\end{array}$ \\
Premadasa Mudunkotuwa & $\begin{array}{l}\text { Has contributed in the designing and interpreting data and giving important intellectual content } \\
\text { especially on aspects in music therapy. }\end{array}$ \\
\hline
\end{tabular}

